МИНИСТЕРСТВО ОБРАЗОВАНИЯ И НАУКИ РОССИЙСКОЙ ФЕДЕРАЦИИ

ТОМСКИЙ ГОСУДАРСТВЕННЫЙ УНИВЕРСИТЕТ

\title{
МАТЕРИАЛЫ
}

VIII Международной молодежной научной конференции

«МАТЕМАТИЧЕСКОЕ

И ПРОГРАММНОЕ ОБЕСПЕЧЕНИЕ

ИНФОРМАЦИОННЫХ, ТЕХНИЧЕСКИХ

И ЭКОНОМИЧЕСКИХ СИСТЕМ»

Томск, 26-30 мая 2021 г.

Под общей редакиией И.С. Шмырина

Томск

Издательство Томского государственного университета 2021 


\section{EFFICIENT FPGA IMPLEMENTATION OF A RECONFIGURABLE FSM BASED ON SUBSTITUTIONS}

\section{Razenkov S.I.}

Tomsk State University

sirazenkov@stud.tsu.ru

\section{Introduction}

Reconfigurable finite-state machines (R-FSMs) are used for designing complex digital systems with modifiable behavior. There exist various kinds of R-FSMs: Self-R-FSM [1], transition-based R-FSM [2], R-FSM with input multiplexing and state-based input selection architecture [3], R-FSM based on substitutions [4]. The R-FSM based on substitutions can find application in cryptography.

In this paper, R-FSM based on substitutions is implemented on an FPGA platform. Substitution representation techniques are compared, namely table representation, system of Boolean functions (disjunctive/algebraic normal forms), formulas with specific operations (ARX, butterfly structure). To estimate performance and resource utilization of a design we use following parameters: maximum path delay, maximum clock frequency, number of LookUp-Tables (LUTs) used in design implementation.

\section{Reconfigurable finite-state machine based on 4-bit substitutions}

Architecture of the R-FSM based on substitutions is presented on Fig. 1. Substitutions Sub $X$, Sub $Y, \operatorname{Sub} S$ are modifiable and Sub 1, Sub 2, ..., Sub $N$ are fixed. Two multiplexers $M 1$ and $M 2$ are used for building the output and state-transition functions, respectively. The current state of the R-FSM is stored in the register Reg. Input alphabet, set of states and output alphabet and are all sets of numbers with $\log _{2} N$ bit size.

Configuration of the R-FSM is done by initializing the modifiable substitutions with the keys $\left(K_{X}, K_{Y}, K_{S}\right)$. As a result, we have a strongly connected, reduced and reversible FSM [4], which can be used in FSM-based ciphers, particularly in Zakrevskij cipher [5].

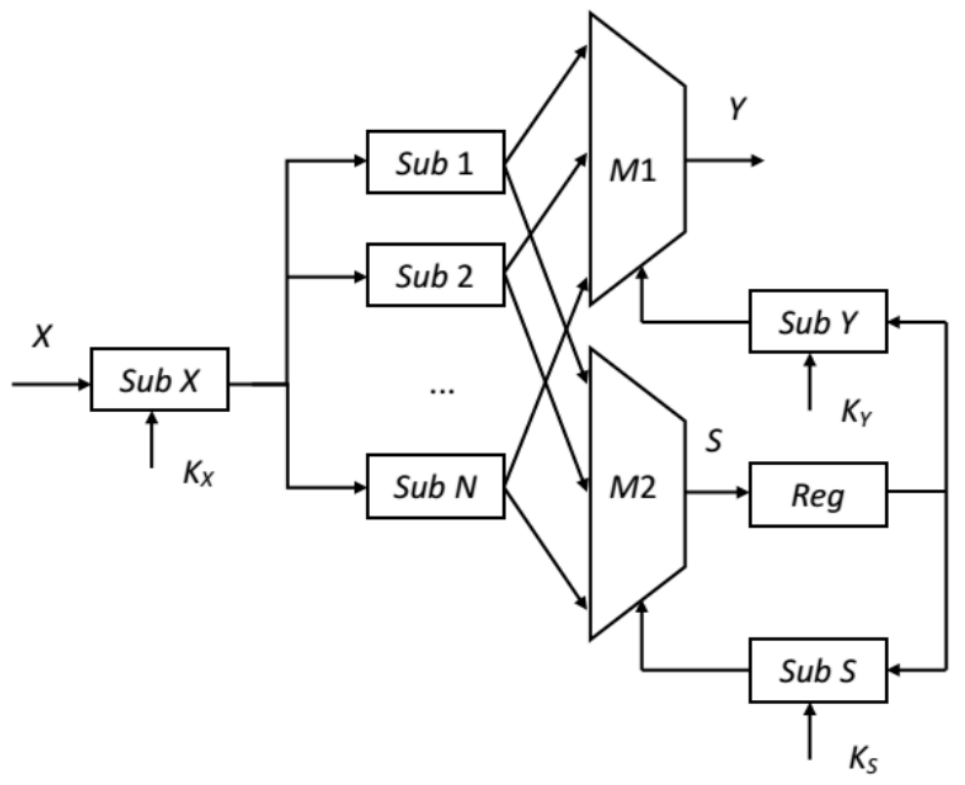

Fig. 1. Structure of the R-FSM based on substitutions 
Input alphabet, set of states and output alphabet in our FPGA implementation are sets of 4-bit numbers with cardinality equal to 16 . Thus, each substitution in the R-FSM takes a 4-bit input and transforms it into a 4-bit output. The modifiable substitution is implemented as a block of RAM memory [6]. Also a multiplexer with 16 4-bit data inputs and a single 4-bit select input was designed. The current state of the R-FSM is stored in a register with 4 flipflops.

\section{Fixed substitutions representation techniques}

\subsection{Table representation}

The most common way to represent a substitution is a table which shows the mapping directly. In hardware description language notation it can be described as: RAM memory, ROM memory (case statement) [6], and directly as a substitution table (selected signal assignment statement [6]). It turned out that the last two approaches synthesize in a same circuit. When we describe a substitution as RAM memory, the specially configured LUT (Look-Up-Table) elements are used, which behave as distributed RAM memory [7]. In all other cases presented in this paper we simply obtain a combinational circuit made of LUT elements. LUT is the main resource of an FPGA. It is a logic element which can implement an arbitrary Boolean function of a fixed number of inputs. Here is an example of table representation:

$$
\left(\begin{array}{cccccccccccccccc}
0 & 1 & 2 & 3 & 4 & 5 & 6 & 7 & 8 & 9 & 10 & 11 & 12 & 13 & 14 & 15 \\
13 & 5 & 0 & 6 & 7 & 15 & 14 & 8 & 4 & 2 & 9 & 1 & 10 & 12 & 3 & 11
\end{array}\right) .
$$

\subsection{System of Boolean functions}

Boolean function is a function which maps a set of Boolean values to a single Boolean value: $\{0,1\}^{n} \rightarrow\{0,1\}$, where $n$ is a non-negative integer. System of Boolean functions is a finite set of Boolean functions. If we take a substitution table and change the decimal number representation to the binary form, we obtain a set of Boolean functions each corresponding to a bit of the substitution result. The number of arguments that each function takes equals the size of the substitution argument in binary form. In this paper, we represented the Boolean functions in full disjunctive normal form (FDNF) and algebraic normal form (ANF). For example, substitution (1) can be represented as:

$$
\left\{\begin{array}{l}
S_{0}(X)=1 \oplus x_{1} \oplus x_{3}, \\
S_{1}(X)=\left(x_{0} \wedge x_{1}\right) \oplus x_{2} \oplus\left(x_{0} \wedge x_{3}\right), \\
S_{2}(X)=1 \oplus x_{1} \oplus\left(x_{0} \wedge x_{1}\right) \oplus\left(x_{1} \wedge x_{2}\right) \oplus\left(x_{0} \wedge x_{3}\right) \oplus\left(x_{2} \wedge x_{3}\right), \\
S_{3}(X)=1 \oplus x_{0} \oplus x_{1} \oplus\left(x_{0} \wedge x_{1}\right) \oplus x_{2} \oplus x_{3} \oplus\left(x_{0} \wedge x_{3}\right),
\end{array}\right.
$$

where $X=\left(x_{3}, x_{2}, x_{1}, x_{0}\right)$ is a 4-bit argument and $S(X)=\left(S_{3}(X), S_{2}(X), S_{1}(X), S_{0}(X)\right)$ is the substitution result; $x_{i}$ and $S_{j}(x)$ are the $i$-th and $j$-th bits of the argument $x$ and result $S(x)$ respectively, counting from the least significant bit.

\subsection{Formula (ARX, butterfly structure)}

Some substitutions can be described as formulas with specific operations: modular addition, bitwise XOR, finite field multiplication, etc. In this paper, we implemented ARX-based substitutions [8] and substitutions with butterfly structure [9]. However, instead of proposed 8-bit substitutions, we implemented 4-bit substitutions with similar structure.

For example, substitution (1) can be described with a round function $g(X)$ which runs 5 times:

$$
\begin{gathered}
g(X)=f_{2} \circ f_{1}(X), \\
f_{2}(X)=\left(b\left(X_{1}\right), b\left(\left(\left(\left(X_{2} \square 1\right)+2\right) \bmod 4\right) \oplus b\left(X_{1}\right)\right)\right), \\
f_{1}(X)=\left(b\left(\left(\left(X_{1} \square 1\right)+X_{2}\right) \bmod 4\right), b\left(X_{2}\right)\right),
\end{gathered}
$$


where $g(X)$ is a composition of functions $f_{1}$ and $f 2, X$ is a 4-bit argument, $b(X)=\left(x_{3}, x_{2}, x_{1}, x_{0}\right)$ is the binary form of number $X, X \square i$ is right circular shift of number $X$ by $i$ bits, argument $X$ is represented here as a concatenation of two 2-bit binary vectors $b\left(X_{1}\right)=\left(x_{3}, x_{2}\right)$ and $b\left(X_{2}\right)=\left(x_{1}, x_{0}\right): X=\left(b\left(X_{1}\right), b\left(X_{2}\right)\right)$.

\section{FPGA implementation of R-FSM}

The project has been synthesized on Xilinx Artix-7 FPGA. VHDL $[6,10]$ description of the R-FSM was made and simulated in Vivado Design Suite developer tool [11].

S-boxes of various ciphers (DES, Gift, PRIDE, PRINCE, KLEIN, NOEKEON, Piccolo) and some randomly created substitutions which, in contrast, can also be described with formulas, are taken and used as fixed substitutions. In cryptography, an S-box (substitution-box) is a basic component of block ciphers. There are many ciphers with S-boxes mapping 4-bit input into 4-bit output. The ciphers use tables to represent S-boxes.

We use tool for creating a substitution table if there is given an ARX-formula or butterfly structure and an automatic VHDL code generator which produces VHDL code for a substitution table.

Various substitution representation techniques (table, system of Boolean functions, formula) are compared. Efficiency is determined by evaluating timing (Tab. 1) and utilization parameters (Tab. 2) of the implemented design which include: maximum path delay, maximum clock frequency, number of LUTs used in design.

Timing parameters

Table 1

\begin{tabular}{|c|c|c|c|}
\hline Substitutions & Representation technique & Max. delay & Max. clock frequency \\
\hline \multirow{3}{*}{ ARX-based substitutions } & RAM memory & $14.385 \mathrm{~ns}$ & $69.516 \mathrm{MHz}$ \\
\cline { 2 - 4 } & ROM memory / Substitution table & $14.285 \mathrm{~ns}$ & $70.003 \mathrm{MHz}$ \\
\cline { 2 - 4 } & Formula & $13.805 \mathrm{~ns}$ & $72.437 \mathrm{MHz}$ \\
\cline { 2 - 4 } & FDNF & $14.035 \mathrm{~ns}$ & $71.250 \mathrm{MHz}$ \\
\cline { 2 - 4 } & ANF & $14.125 \mathrm{~ns}$ & $70.796 \mathrm{MHz}$ \\
\hline Substitutions with butterfly structure & RAM memory & $14.385 \mathrm{~ns}$ & $69.516 \mathrm{MHz}$ \\
\cline { 2 - 4 } & ROM memory / Substitution table & $14.186 \mathrm{~ns}$ & $70.492 \mathrm{MHz}$ \\
\cline { 2 - 4 } & Formula & $13.859 \mathrm{~ns}$ & $72.155 \mathrm{MHz}$ \\
\cline { 2 - 4 } & FDNF & $13.808 \mathrm{~ns}$ & $72.421 \mathrm{MHz}$ \\
\cline { 2 - 4 } & ANF & $14.312 \mathrm{~ns}$ & $69.871 \mathrm{MHz}$ \\
\hline \multirow{4}{*}{ S-boxes } & RAM memory & $14.385 \mathrm{~ns}$ & $69.516 \mathrm{MHz}$ \\
\cline { 2 - 4 } & ROM memory / Substitution table & $14.350 \mathrm{~ns}$ & $69.686 \mathrm{MHz}$ \\
\cline { 2 - 4 } & FDNF & $13.766 \mathrm{~ns}$ & $72.642 \mathrm{MHz}$ \\
\cline { 2 - 4 } & ANF & $13.812 \mathrm{~ns}$ & $72.400 \mathrm{MHz}$ \\
\hline
\end{tabular}

Utilization parameters

\begin{tabular}{|c|c|c|}
\hline Substitutions & Representation technique & LUT \\
\hline \multirow{5}{*}{ ARX-based substitutions } & RAM memory & 109 \\
\hline & ROM memory / Substitution table & \multirow{4}{*}{74} \\
\hline & Formula & \\
\hline & FDNF & \\
\hline & ANF & \\
\hline \multirow[t]{5}{*}{ Substitutions with butterfly structure } & RAM memory & 109 \\
\hline & ROM memory / Substitution table & \multirow{4}{*}{71} \\
\hline & Formula & \\
\hline & FDNF & \\
\hline & ANF & \\
\hline \multirow[t]{4}{*}{ S-boxes } & RAM memory & 109 \\
\hline & ROM memory / Substitution table & \multirow{3}{*}{76} \\
\hline & FDNF & \\
\hline & ANF & \\
\hline
\end{tabular}


All implementations also use 4 flip-flops and dedicated multiplexers F7 MUX, F8 MUX [7] (16 and 8, respectively).

\title{
Conclusion
}

This article presents research results on different substitution representation techniques for FPGA implementation of a reconfigurable finite-state machine based on 4-bit substitutions. Various substitution representation techniques are used, namely table representation (memory, substitution table), ARX-formula, butterfly structure, system of Boolean functions (disjunctive/algebraic normal forms). Nevertheless, all designs, except the one, where substitutions are described as RAM memory, have roughly the same utilization and timing parameters. However, when the fixed substitutions are designed as RAM memory, the R-FSM implementation requires significantly more LUTs and has a slightly lower maximum clock frequency.

\section{REFERENCES}

1. Koster M., Teich J. (Self-)reconfigurable finite state machines: theory and implementation // Proceedings 2002 Design, Automation and Test in Europe Conference and Exhibition - 2002 - P. 559-566.

2. Glaser J., Damm M., Haase J., Grimm C. TR-FSM: Transition-based Reconfigurable finite state machine // ACM Transactions on Reconfigurable Technology and Systems (TRETS). - 2011. - V. 4. - № 3. - Article №23.

3. Das N., Aruna Priya P. FPGA Implementation of Reconfigurable Finite State Machine with Input Multiplexing Architecture Using Hungarian Method // International Journal of Reconfigurable Computing. - 2018. - V. 2018. - Article ID $6831901-15 \mathrm{p}$.

4. Trenkaev V.N. Reconfigurable finite-state machine based on substitutions // Prikladnaya Diskretnaya Matematika. Prilozhenie. - 2019. - № 12. - P. 192-193.

5. Trenkaev V.N. Zakrevskij's cipher based on reconfigurable FSM // Prikladnaya Diskretnaya Matematika. 2010. - № 3(9). - P. 69-76. 2013. $-720 \mathrm{p}$

6. Harris D.M., Harris S.L. Digital Design and Computer Architecture. Second edition. - Morgan Kaufmann,

7. Series FPGAs Configurable Logic Block $\quad$ (UG474) https://www.xilinx.com/support/documentation/user_guides/ug474_7Series_CLB.pdf

8. Komissarov S.M. On algorithmic implementation of 16-bit S-boxes with ARX and Butterfly structures // Prik1. Diskr. Mat. Suppl. - 2019-12- P. 101-107.

9. Fomin D.B. New classes of 8-bit permutations based on a butterfly structure // Mat. Vopr. Kriptogr. - 2019. V. 10. - Is. 2. - P. 169-180.

10. Ashenden P.J. The designer's guide to VHDL. 3rd ed. - Elsevier Inc., 2008

11. Vivado Design Suite User Guide : Synthesis (UG901) - URL: https://www.xilinx.com/support/documentation/sw_manuals/xilinx2020_2/ug901-vivado-synthesis.pdf

DOI: $10.17223 / 978-5-907442-42-9-2021-36$

\section{ЧТЕНИЕ ДАННЫХ С ЭКСПЕРИМЕНТАЛЬНОЙ УСТАНОВКИ}

\author{
Безходарнов Н.И., Самохина С.И. \\ Томский государственный университет \\ nblaaa@mail.ru
}

\section{Введение}

В одной из лабораторий Томского кардиологического центра ведётся работа по снятию показаний с нагруженной сердечной мышцы. Для этого в лаборатории имеется оборудование, предназначенное для экспериментов с сердечной мышцей. Именно для этой установки была поставлена задача разработать информационную систему, в которой выполняется снятие показаний при проведении эксперимента, их оцифровка и математическая обработка. Установка для экспериментов состоит из считывающего устройства, модификаторов сигнала и преобразователя аналогового сигнала в цифровой. Для считывания данных необходимо связаться с преобразователем. Далее полученная кривая аппроксимируется с помощью метода сетки, выполняется анализ полученных данных и визуализация. 